\title{
Construction of a Transcription Map Surrounding the BRCA1 Locus of Human Chromosome 17
}

\author{
Lawrence C. Brody, ${ }^{* 1}$ Kenneth J. Abel, $\dagger \neq \neq^{1}$ Lucio H. Castilla, ${ }^{\star}, 1$ Fergus J. Couch, $\S^{\prime 1}$ \\ DAWN R. MCKINLEY, ${ }^{\star}$ GUIYING YIN, + PEgGY P. Ho, SOFIA MERAJVER, \\ Settara C. Chandrasekharappa, * Junzhe Xu, $₫$ Jeffery L. Cole, † Jeffery P. Struewing, \\ John M. Valdes, † Francis S. Collins, ${ }^{*, 2}$ and Barbara L. Weber $\S$ \\ * The National Center for Human Genome Research. "Genetic Epidemiology Branch, National Cancer Institute, National Institutes of \\ Health, Bethesda, Maryland 20892; Departments of $q$ Medicine and H Human Genetics and $\neq$ The Human Genome Center, \\ University of Michigan, Ann Arbor, Michigan 48109; and §Departments of internal Medicine and Genetics, \\ University of Pennsylvania, Philadelphia, Pennsylvania 19104
}

Received October 24, 1994; revised November 28, 1994

\begin{abstract}
We have used a combination of methods (exon amplification, direct selection, direct screening, evolutionary conservation, island rescue-PCR, and direct sequence analysis) to survey approximately $600 \mathrm{~kb}$ of genomic DNA surrounding the BRCA1 gene for transcribed sequences. We have cloned a set of fragments representing at least 26 genes. The DNA sequence of these clones reveals that 5 are previously cloned genes; the precise chromosomal location of 2 was previously unknown, and 3 have been cloned and mapped by others to this interval. Three other genes, including $B R C A I$ itself, have recently been mapped independently to this region. Sequences from 11 genes are similar but not identical matches to known genes; 5 of these appear to be the human homologues of genes cloned from other species. Another 7 genes have no similarity with known genes. In addition, 39 putative exons and 14 expressed sequence tags have been identified and mapped to individual cosmids. This transcript map provides a detailed description of gene organization for this region of the genome. 1995 Academic Press, Inc.
\end{abstract}

\section{INTRODUCTION}

The generation of transcript maps is an important goal of the human genome project (Collins and Galas, 1993). In addition to detailed genetic and physical maps, a map of transcribed sequences is necessary for understanding genome structure and will aid greatly in the isolation of the genes for inherited traits. As part of our effort to isolate the breast cancer susceptibility gene, $B R C A 1$, we have constructed a transcript map

\footnotetext{
${ }^{1}$ Contributed equally to this work.

${ }^{2}$ To whom correspondence should be addressed at The National Center for Human Genome Research, National Institutes of Health, Building 49, Room 3A18, 9000 Rockville Pike, Bethesda, Maryland 20892. Telephone: (301) 496-0844. Fax: (301) 402-4929.
}

covering approximately $1 \mathrm{Mb}$ of chromosome $17 \mathrm{q} 21$. The mapping of the BRCA1 gene to chromosome 17q (Hall et al., 1990; Narod et al., 1991) and further refinement of its location by genetic recombination allowed a minimal candidate interval to be defined (Bowcock et al., 1993; Easton et al., 1993; Chamberlain et al., 1993; Simard et al., 1993; Smith et al., 1994). This interval spans approximately $1 \mathrm{cM}$ of chromosome 17 . Since on average $1 \mathrm{cM}$ equals approximately $1 \mathrm{Mb}$, this amount of DNA should be amenable to positional cloning efforts (Collins, 1992). The first step of such an effort is construction of a physical contig of DNA included in the interval. We and others (Albertsen et al., 1994) have constructed physical maps of this candidate interval, and the accompanying paper (Couch et al., 1995) presents a yeast artificial chromosome (YAC)-, P1-, and cosmid-based contig of this region. Although by its nature a positional cloning approach is targeted toward the isolation of a single gene, a successful outcome in many cases depends upon the isolation of most of the genes contained in the candidate interval.

There are several methods available for isolating transcribed sequences from large genomic regions. Exon amplification/exon trapping (Duyk et al., 1990; Buckler et al., 1991; Krizman and Berget, 1993), direct selection (Parimoo et al., 1991; Lovett et al., 1991), direct screening (Wallace $e t$ al., 1990), evolutionary conservation, genomic sequencing (Sulston et al., 1992; Oliver et al., 1992), and CpG island-based (Patel et al., 1991; Valdes et al., 1994) methods have all been used to identify the transcribed portions of genomic DNA. The advantages and disadvantages of these methods have been described (Collins, 1992; Weber et al., 1994). No single method has been shown to be capable of isolating $100 \%$ of the transcripts from a given genomic interval of this size. For this reason our collaborative multi-institutional effort employed six methods of transcript identification in parallel. Exon amplification, direct selection, and direct screening were performed us- 
ing cosmids representing the majority of our contig. Transcript isolation by island rescue PCR and evolutionary conservation was carried out on a subset of these. In the accompanying papers, Osborne-Lawrence et al. (1995) and Friedman et al. (1995) report on extensive direct selection experiments and YAC-based direct cDNA library screening, respectively. These studies utilized the same collection of genomic clones as were used in this study (Couch et al., 1995). Therefore, some conclusions can be drawn as to the specificity and sensitivity of these methods as the result of this comparison.

While recogniizing that these methods can be applied to either YACs or cosmids, we have derived the majority of the data described here from cosmid material due to its relative ease of manipulation. We present here a transcript map of the BRCA1 region. In the interval bounded by the genes $E D H 17 B 2$ (17 $\beta$-hydroxysteroid dehydrogenase II) and $P P Y$ (pancreatic polypeptide), we have isolated 26 genes. Of these, 19 have similarities or identities to known genes, while 7 appear to be novel genes. In addition, 53 unique exons and cDNA fragments (expressed sequence tags, ESTs) have been isolated and mapped to specific cosmids in the contig.

\section{MATERIALS AND METHODS}

Molecular biology techniques. Except as noted, all molecular manipulations (cloning, phage library screening, PCR) were performed using standard methods (Sambrook et al, 1989).

Cosmids and YACs. The cloning and construction of the BRCA1region cosmid, P1, and YAC contig is described by Couch et al. (1995). Well locations of the cosmids presented here have been maintained from the original library provided by L. Deaven (Los Alamos National Laboratory).

cDNA libraries. A human breast ( $\mathrm{\lambda gt} 11$ vector, oligo(dT)-primed) cDNA library was constructed at the University of Michigan Genome Center (Swaroop and $\mathrm{Xu}, 1993$ ). Human fetal brain (Stratagene, LambdaZAPII vector, random and dT primed), normal human ovary (Stratagene, LambdaUNI.ZAPXR, dT primed), and normal human breast (Clontech, $\lambda g t 10$, random primed) cDNA libraries were purchased. A human endothelial cell cDNA library ( $\lambda \mathrm{gt} 11$, random and $\mathrm{d} T$ primed) was a gift from $\mathrm{D}$. Ginsburg. For library screening 30,000 to 50,000 plaques were plated per $150-\mathrm{mm}$ dish and transferred to Hybond-N (Amersham) membranes. Three to five hundred thousand plaque forming units were screened with each probe.

Chromosome mapping panels. The chromosomal location of all clones was verified by at least one of two methods. The first was Southern blotting to a somatic cell hybrid mapping panel containing the following human-rodent somatic cell hybrid lines: 7AE4 (containing an intact human chromosome 17; Leach et al., 1989), 12.3B5 (17p-q12, GM10659), MH41 (17q23.2-qter, GM10502), and L(17n)C (chromosome 17q; Leach et al., 1989). An appropriate hybridization pattern allowed assignment to human $17 \mathrm{q} 21-\mathrm{q} 23$. The second method employed a screening Southern blot containing two samples (plus a molecular weight standard). Lane 1 contained total human genomic DNA, and lane 2 contained DNA from a pool of 400 cosmids from the region. The cosmid sample was "normalized" for copy number to the genomic samples ( $10 \mu \mathrm{g} /$ lane) by loading less cosmid pool DNA (10 ng/lane). These samples were restricted with Pst I, and multiple "two-lane" blots were produced. The cosmid lane served to represent the genomic interval of interest. Clones were said to map to the region if equivalent hybridization bands were observed in the cosmid and human genomic lanes. Exons and cDNA clones were then mapped to individual cosmids by colony hybridization to cosmid arrays as previously described (Couch et al., 1995).

Exon amplification. Exon amplification was performed essen- tially as previously described (Buckler et al., 1991) using the modified cloning vector pSPL3 (Church et al., 1994). For a detailed description and discussion of the exon amplification methods, cosmids employed, and characterization of isolated exons, see Abel et al. (1994). Briefly, pools of $6-10$ cosmids were used for each exon amplification reaction. These pools included many redundant cosmids not shown in the minimal set (Couch et al., 1995, F'ig. 1). Plasmid clones containing putative exons derived from these experiments were isolated to microtiter dishes to be further characterized. Filter replicas of these dishes were then hybridized sequentially with human Cot1 DNA, the amplification vector, and PCR-amplified inserts of individual clones. These hybridizations allowed the identification of clones containing human reiterated sequences, cloning artifacts, and redundant exons, respectively. The resulting set of unique clones is shown in Fig. 1. Clones containing trapped exons were mapped as described above and used as probes to screen cDNA libraries.

Direct selection. Direct selection was carried out using the magnetic bead capture protocol as described (Tagle et al., 1993; Couch et al., 1994). Cosmid DNAs spanning the region between cosmids $96 \mathrm{H} 6$ and 119D4 (Fig. 1) were placed in two pools (seven cosmids per pool) and digested with Sau3AI or $A l u I$. After linker addition and amplification with biotinylated primers, the cosmid DNA was hybridized in solution to an excess of amplified breast cDNA library inserts. Specifically bound material was eluted at high temperature and cloned into plasmid vectors. Inserts from these clones were then analyzed as outlined above.

Direct screening. Cusmids were digested with the restriction enzyme Not I, and inserts were isolated from low-melting-temperature agarose (SeaPlaque, FMC) and random-prime labeled individually using standard methods (Feinberg and Vogelstein, 1983). The labeled products of up to five cosmids were then pooled. Pooled probes were mixed with $150 \mu \mathrm{g}$ of sheared human placental and $300 \mu \mathrm{g}$ of sheared salmon sperm DNAs in TE ( $500 \mu \mathrm{l})$. After boiling ( $10 \mathrm{~min})$, the DNAs were preannealed at $65^{\circ} \mathrm{C}$ for $1 \mathrm{~h}$. Prehybridization and hybridization of cDNA library filters was carried out in 7\% SDS, $0.25 \mathrm{M} \mathrm{Na}_{2} \mathrm{HPO}_{4}$ $1 \mathrm{~m} M$ EDTA, and $1 \%$ bovine serum albumin. Filters were washed in $2 \times \mathrm{SSC}, 1 \% \mathrm{SDS}$ at $65^{\circ} \mathrm{C}(2 \times, 30 \mathrm{~min})$ prior to exposing to $\mathrm{X}$-ray film. After a 24-h exposure, primary plaque signal intensity varied from just over background to several-fold over background.

Evolutionary conservation and island rescue PCR. Cosmid fragments containing single-copy DNA were isolated by subcloning restriction fragments that failed to hybridize with labeled total human genomic DNA. These subclones were used to probe Southern blots containing human, gorilla, rodent (mouse, hamster, and rat), and Torpedo californica (Pacific electric ray) DNA. Probes hybridizing to humans and other species were sequenced.

The generation of island rescue PCR (IR-PCR) probes from the $300-$ $\mathrm{kb}$, nonchimeric YAC, $26 \mathrm{~F} 3$, has been previously reported (Valdes $e t$ al., 1994).

Sequence analysis. Double-stranded DNA sequencing was performed on an automated sequencer (Applied Biosystems or Pharmacia) using fluorescence methodology as recommended by the manufacturer. The BLASTN (Altschul et al., 1990) and BLASTX (Gish and States, 1993) programs were used to search GenBank (National Center for Biotechnology Information) with sequence from putative transcribed clones. Gene Recognition and Analysis Internet Link (GRAIL, Uberbacher and Mural, 1991) program version 1.2 was accessed through the XGRAIL client (Shah et al., 1994) on a Sun Sparc10 workstation. GRAIL 2 analysis was performed on the $21 \mathrm{~kb}$ of genomic sequence from the EDI17B2 locus. This sequence was deposited in GenBank by Peltoketo et al. (1988) (Accession No. M84472). The sequences of clones reported in Table 1 have been deposited with GenBank.

\section{RESULTS AND DISCUSSION}

A map of transcripts is shown in Fig. 1. More detailed information on individual transcripts is listed in Table 1. For orientation purposes, the clones are listed in centromere to telomere order. The transcripts are de- 


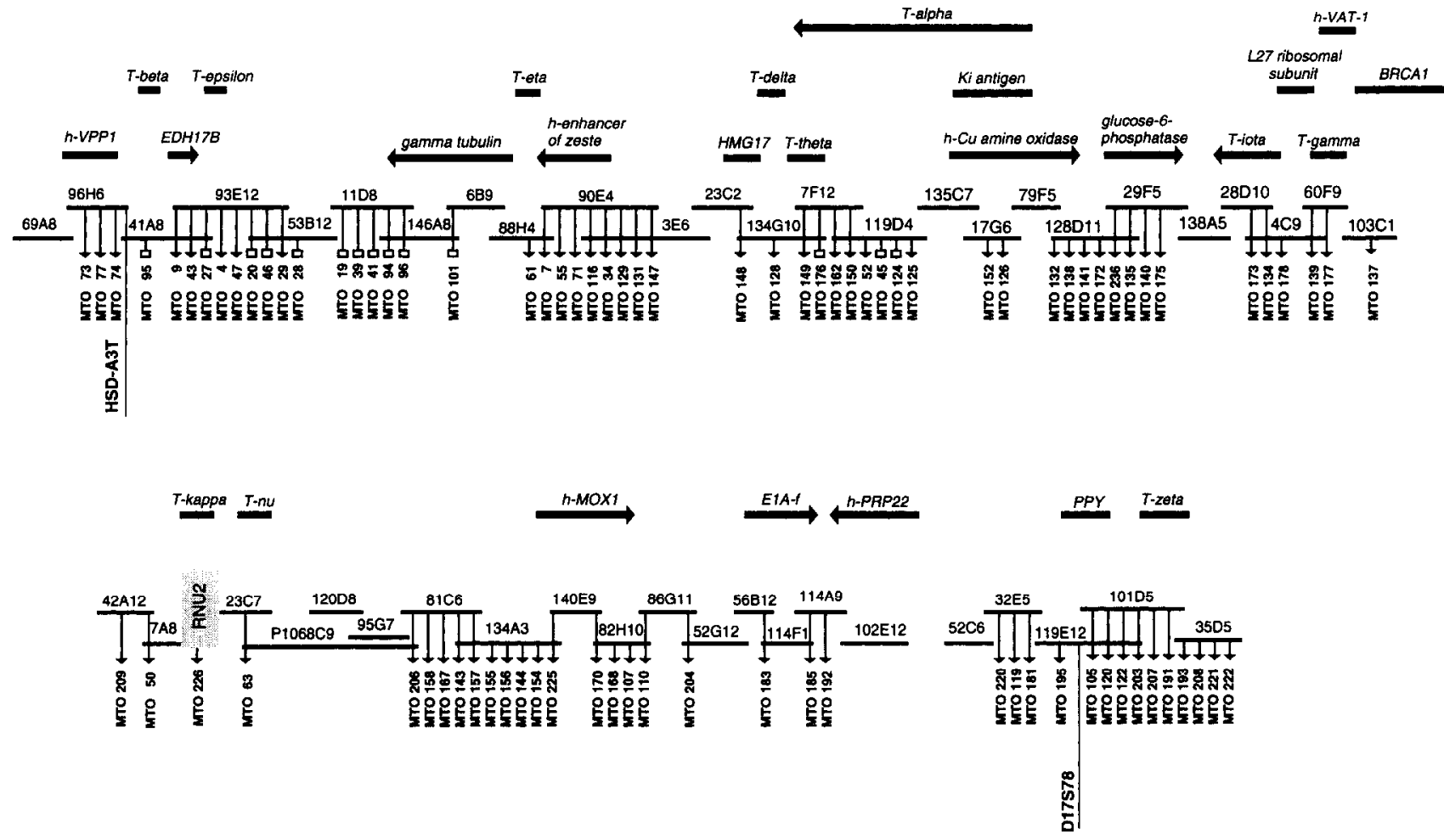

FIG. 1. Schematic diagram of the transcript map in the BRCA1 region between markers HSD-A3T (Friedman et al., 1993) and the $P P Y$ gene. The minimal cosmid contig is represented by thin horizontal bars (Couch et al., 1995) from centromeric end (top left) to telomeric end (bottom right). Cloned transcripts are represented by thick bars. Arrows at the ends of transcripts indicate the direction of transcription, if known. Previously unidentified genes are named with the prefix "T" (transcript) and a Grcck lettcr. Human homologues of genes cloned from other species are named with the prefix " $h$ " (human). Downward vertical thin arrows indicate the map location of trapped exons, and vertical bars with squares direct selected cDNA clones. The RNU2 region is represented by a gray box (see text). Cosmids, genes, and exons are not drawn to scale. Genes are drawn to represent accurately the hybridization of cDNA clones to specific cosmids. The overlapping cosmid and P1 contig contains two gaps, one at the break of the top right edge and one between cosmids $102 \mathrm{E} 12$ and $52 \mathrm{C} 6$ on the bottom.

scribed below, first in terms of isolation methods and then by sequence information.

\section{Evaluation of Transcription Isolation Methods}

Exon amplification. Cosmid DNAs representing 39 of the 45 cosmids in our contig were used as templates for exon amplification. Two exon amplification experiments were performed: the first using unordered cosmid pools and the second with cosmids pooled by their contig location (Abel et al., 1994). Over 2000 primary clones were isolated and arrayed in microtiter dishes. From this starting material a nonredundant collection of exons was derived. This set contained a total of 76 exons that mapped to the region of interest (Fig. 1). Exon amplification was applied more extensively than any other method presented here and proved highly effective. Putative exons were isolated from almost every cosmid tested. Trapped exons were isolated as plasmid clones that can be readily sequenced, thus allowing rapid comparison to nucleotide databases. Because they are directionally cloned, the orientation of transcription can be determined from this sequence. An added advantage of this method is the ease of determining intron-exon borders by comparing the sequence of trapped exons to cDNA sequences. In several cases, multiple unique exon clones were shown to be con- tained in a single cDNA (E1A-f, glucose-6-phosphatase, human Enhancer of zeste, and others). In this study, the major disadvantages of transcript isolation by exon amplification was the small size of some of the trapped exons. Although the average trapped exon was $200 \mathrm{bp}$, the distribution was clearly skewed toward the 100- to 150 -bp range (median $=130 ;$ Abel et al., 1994). In the case of the BRCA1 gene, we isolated clones corresponding to exons 20 (84 bp) and 22 (74 bp) (Miki et al., 1994). Clones of this size are difficult to use as hybridization probes for screening cDNA libraries using conventional methods.

Direct selection. A total of 14 cosmids were digested with Sau3AI and $A l u$ I and hybridized to PCR-amplified inserts from a breast cDNA library for the direct selection of clones. Of 32 clones analyzed from one experiment, 23 (72\%) mapped to the region of interest of chromosome 17, although more than half (14) of these contained Alu sequences in addition to single-copy sequence (Couch et al., 1995). Due to the difficulty of using these clones in hybridization experiments, they were not characterized further. This set of clones identified 2 genes that were not isolated by other methods (Table 1).

Direct screening. The inserts of 25 cosmids represented in the minimal contig were used to probe the 
TABLE 1

Summary of Isolated BRCA1-Region Clones

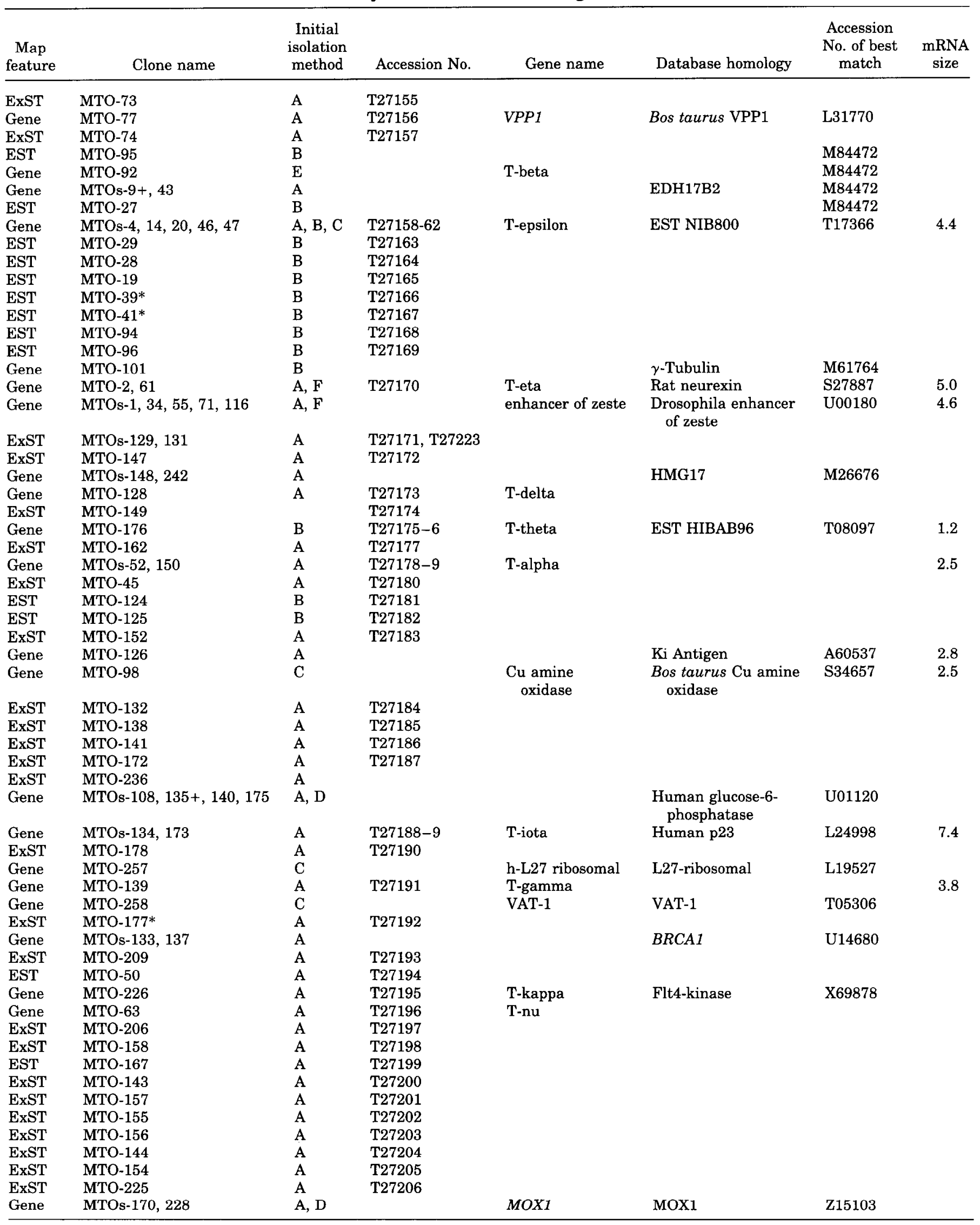


TABLE 1-Continued

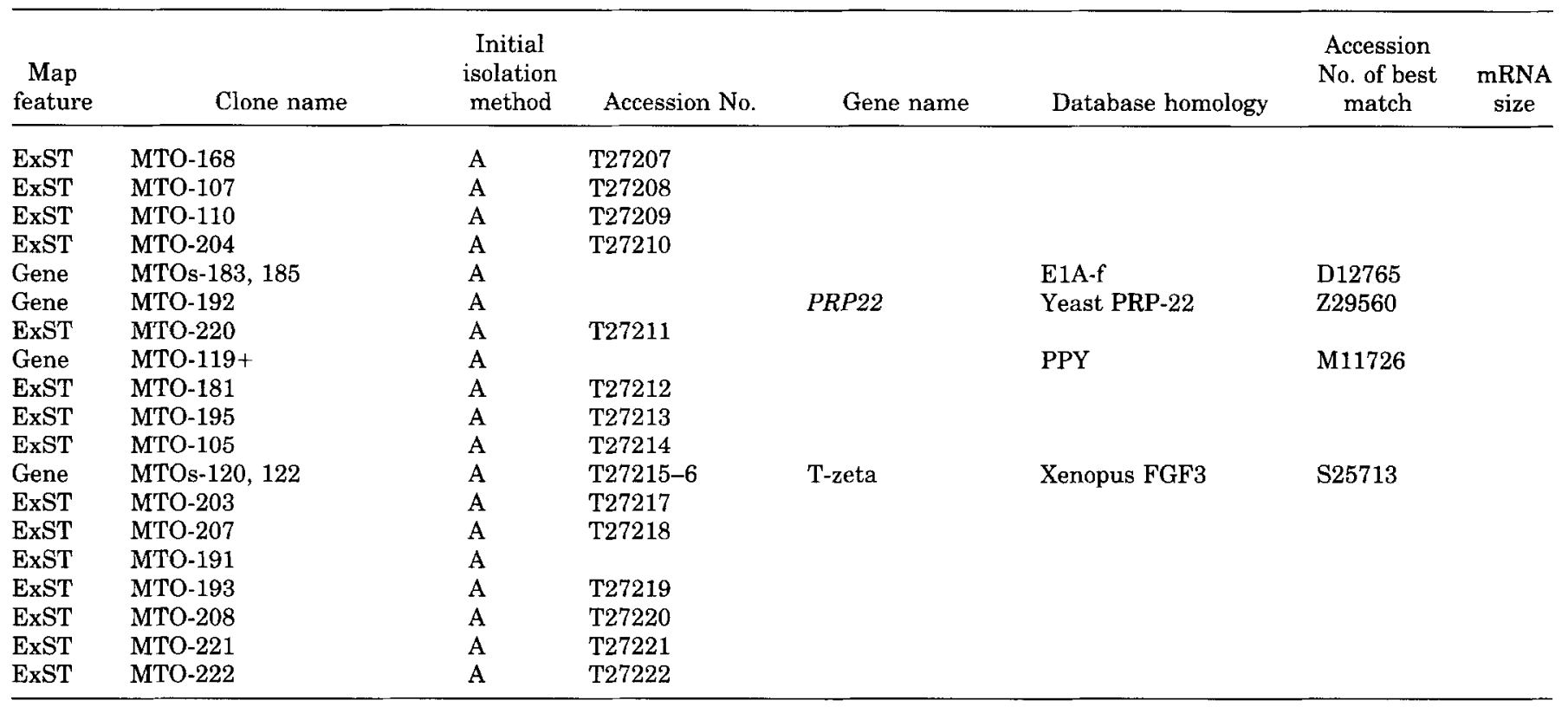

Note. Rows containing map features are in centromere to telomere order as in Fig. 1. Clones marked with an asterisk contain repetitive and single-copy sequences (see text). A plus sign is used to denote exon clones that have been trapped from the minus strand of known genes (see text). Initial isolation methods are as follows: A, exon amplification; B, direct selection; C, direct screening; D, evolutionary conservation; E, GRAIL; F, island rescue PCR. Accession numbers are not given when the sequence of clones presented here was identical to those in GenBank. Likewise, a name does not appear in the gene name column if the nucleotide sequence of a cloned fragment was identical to the sequence of the database entry. Blank entries in the database homology column indicate that no significant matches were found. The accession number of the best GenBank match is shown. In many cases additional GenBank entries scored nearly as high as the best match. mRNA size is shown if the isolated clones were used to probe Northern blots. Blank entries indicate that a Northern blot was nul performed.

oligo(dT)-primed, normal breast cDNA library. These screens resulted in the isolation of four genes. Direct hybridization methods are often complicated by the isolation of transcribed repeats. In this study one cDNA clone, MTO-14, was found to contain a repetitive sequence and adjacent unique sequences. These unique sequences hybridized specifically to the $93 \mathrm{E} 12$ and 41A8 cosmids. In general, direct library screening yielded few genes per pooled cosmid probe. The major disadvantage of this method was its low efficiency of transcript isolation. Its simplicity and the fact that it isolates intact cDNA clones is one advantage of the direct screening method over those described above.

Island rescue and evolutionary conservation. Although these two methods were only applied to three cosmids and one YAC, this application did yield four genes. Island rescue was performed on the 26F3 YAC, resulting in the isolation of two genes from the human endothelial cell cDNA library (Table 1).

Clones containing evolutionarily conserved sequences were isolated as a by-product of experiments aimed at cloning of "single-copy" DNA fragments from the region. In the process of mapping these clones to the chromosome 17 somatic cell hybrid panel, signals were noted in lanes containing the DNA of other vertebrates (Fig. 2A). Subsequent sequence analysis of these clones revealed that two of three clones had significant similarity to sequences in GenBank. A subclone from cosmid 29F5 contains a portion of the glucose-6-phos- phatase gene (Fig. 3), and the subclone spanning cosmids $134 \mathrm{~A} 3,140 \mathrm{E} 9$, and $86 \mathrm{G} 11$ contains a portion of the MOX1 gene (data not shown).

Sequence-based exon prediction. GRAIL analysis of the published 21,788-bp region of genomic DNA containing the $E D H 17 B 1$ and $E D H 17 B 2$ genes predicted the presence of a previously undescribed transcription unit proximal to the EDH17B1 gene (Fig. 4). Three putative exons were amplified from genomic DNA and used to screen a breast cDNA library, resulting in the isolation of several cDNA clones containing the predicted exons spliced together.

Efficiency of transcript isolation. The goal of this study was to isolate the maximum number of transcripts. Transcript identification was carried out as a dynamic process. Regions of the contig in which transcripts were efficiently isolated by the first method applied were not as intensely characterized by additional methods. Products of each of the methods were crosshybridized to each other, and in several cases fragments of the same transcript were isolated by independent methods (Table 1). In the case of glucose-6-phosphatase (Fig. 3), different segments of the same gene were isolated by different methods. Clones isolated in subsequent experiments that were completely contained within existing clones (regardless of the isolation method) were not characterized further and do not appear in Table 1. Therefore, these results cannot be used rigorously to compare transcript isolation meth- 


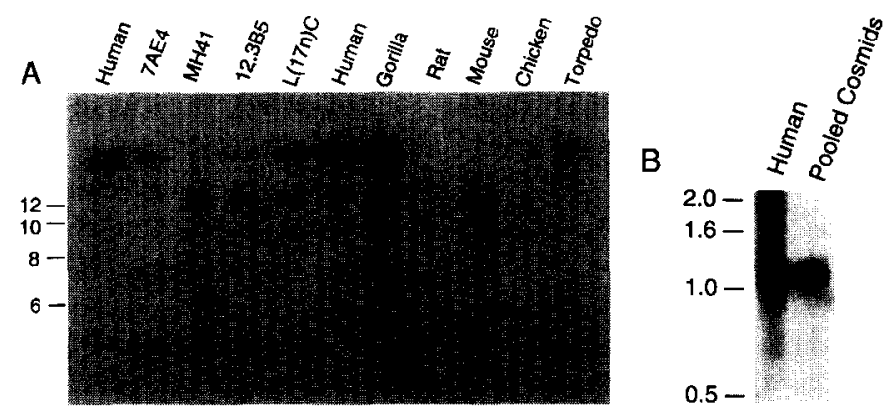

FIG. 2. Mapping panels for the localization of transcripts to the $B R C A 1$ region. (A) Somatic cell hybrid panel. Southern blot analysis using cell lines containing various regions of human chromosome 17 and genomic DNAs (restricted with $X b a \mathrm{I}$ ) from various other species. Cell lines (lanes 2-5) contained the following regions of human chromosome 17 in the specified rodent background: $7 \mathrm{AE} 4$ (intact chromosome 17, rat background), MH41 (17q23.2-qter, mouse background), 12.3B5 (17p-q12, mouse background), and $\mathrm{L}(17 \mathrm{n}) \mathrm{C}(17 \mathrm{q}$, mouse background). The relative migration of the molecular weight marker (in $\mathrm{kb}$ ) is shown to the left. The filter was hybridized with a probe from the MTO-108 clone (contains part of the G6PT gene). A band $(>12 \mathrm{~kb})$ is found in the 7AE4 and $\mathrm{L}(17 \mathrm{n}) \mathrm{C}$ cell lines, as well as in human and gorilla DNA. The absence of this band in the MH41 and $12.3 B 5$ cell lines allows assignment of this clone to the $17 \mathrm{q} 12-\mathrm{q} 22$ interval. A mouse-specific band $(\approx 11 \mathrm{~kb})$ and a rat-specific band $(\approx 7$ $\mathbf{k b}$, visible on longer exposures) are present in hybrid cells with the appropriate backgrounds. The presence of bands in other vertebrate DNAs indicates a high degree of evolutionary conservation of this sequence. (B) An example of a "two-lane" mapping panel (restricted with $P s t \mathrm{I}$ ) as described under Materials and Methods. Lane 1 contains total human genomic DNA $(10 \mu \mathrm{g})$. Lane 2 contains pooled DNA $(10 \mathrm{ng})$ of 400 cosmids from the BRCA1 region. The migration of molecular weight standards $(\mathrm{kb})$ is shown to the left. The blot was hybridized with the probe from the exon clone MTO-110 (169-bp insert $)$. Bands of the same size $(\approx 1.2 \mathrm{~kb})$ are present in the cosmid pool and human genomic lanes, indicating that this exon maps to the interval included in the cosmid contig. The uniform background hybridization in the human lane was often observed when inserts smaller than $200 \mathrm{bp}$ were used as probes.

ods. In most cases, the partial cDNAs were then used to screen cDNA libraries to extend the initial clones.

We have failed to clone fragments of at least two genes known to be in this interval. The VHR phosphatase gene has been independently isolated and localized to this region by Kamb et al. (1994) and Friedman et al. (1995). A 4.3-kb cDNA encoding the putative
CA125 antigen, a B-box protein, has also been mapped to this interval by Campbell et al. (1994) and OsborneLawrence et al. (1995). Both of these genes are known to be represented in our cosmid collection, highlighting the fact that current applications of transcript isolation methodologies are less than $100 \%$ effective.

\section{Characterization of Isolated Transcripts}

Placement of features on the map. Borrowing a term from the cartographer's lexicon, we refer to the transcript clones as "features." For classification purposes we divided the products of our transcript search into three categories: genes, expressed sequence tags (EST), and exon sequence tags (ExST) (Table 1). These features are distributed across the entire contig (Fig. 1). The chromosomal location of clones was first verified by hybridization to somatic cell hybrid panels as described under Materials and Methods (Fig. 2). Higher resolution mapping was achieved by hybridizing individual clones to gridded arrays of the complete cosmid contig. At least one feature was mapped to each cosmid used for transcript searching. The cosmids 120D8, 95G7, $102 \mathrm{E} 12$, and $52 \mathrm{C} 6$ were not used in our transcript isolation effort. The transcript sizes of several genes have been determined by Northern blot analysis (Table 1).

It should be noted that the exact physical distance spanned by these cosmids is not known. Our cosmid contig materials contained three gaps (Couch et al., 1995), one of which is now known to contain the majority of the BRCA1 gene (Miki et al., 1994; Futreal et al., 1994b). The 40 cosmids used for transcript isolation overlap each other to varying extents (Couch et al., 1995). Assuming conservatively that each cosmid represents only $15 \mathrm{~kb}$ of unique genomic DNA (i.e., not found in the adjacent cosmid), we have surveyed approximately $600 \mathrm{~kb}$ of genomic material. This estimate does not include the region containing the RNU2 gene cluster, which is known to contain approximately 20 copies of this gene, spanning $120 \mathrm{~kb}$ of genomic DNA (Westin et al., 1984).

Genes. There are two overlapping criteria by which cloned material was placed into the "gene" category. (1)

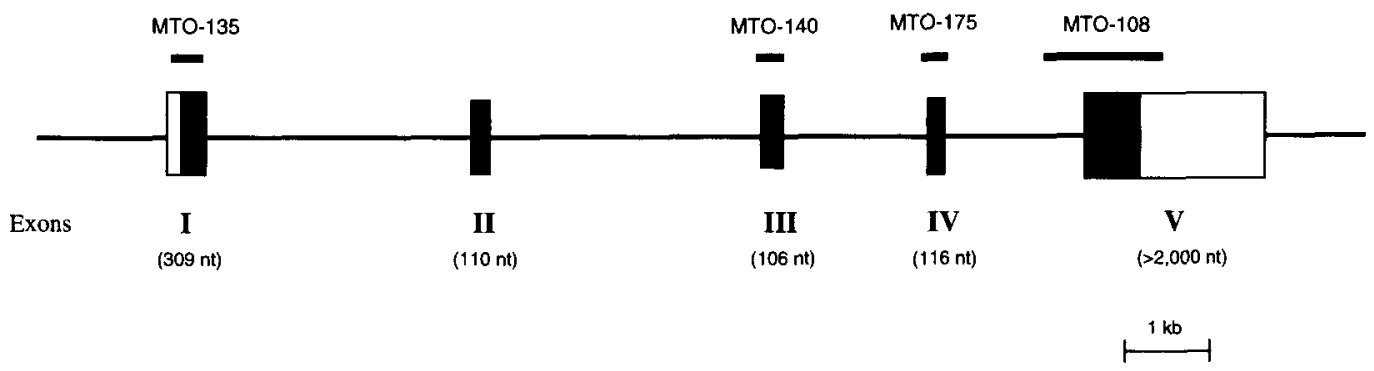

FIG. 3. Schematic diagram of the glucose-6-phosphatase (G6PT) gene adapted from Lei et al. (1993). Exons are represented as boxes. Shaded regions correspond to the translated portion of the G6PT cDNA. Regions of this gene independently cloned in this report are shown above the schematic. Clones MTO-135, -140 , and -175 were isolated by exon amplification. Clones MTO-140 and -175 correspond exactly 10 G6PT exuns III and IV as reported in Lei et al. (1993). The sequence of clone MTO-135 reveals an exact match to nucleotides 134-245 of exon I. Exon I spans from nucleotides 1 to 309 of the G6PT cDNA. Because the exon-amplified fragments are directionally cloned, it can be determined that MTO-135 was originally trapped from the DNA strand opposite to that of G6PT exon I. The clone MTO-108 was isolated as an evolutionarily conserved fragment (1.2-kb SacI, subclone) of the cosmid 29F5. This genomic clone spans part of G6PT intron IV and exon V. 


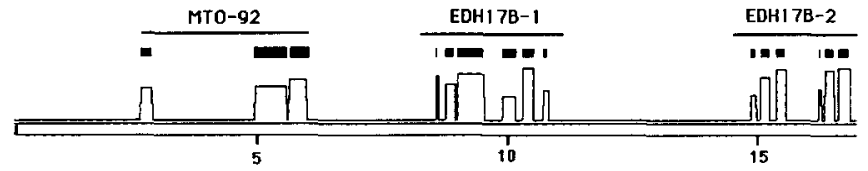

FIG. 4. GRAIL analysis of the genomic sequence containing the $E D H 17 B 1$ and $E D H 17 B 2$ loci. GRAIL 2 analysis was performed on $21 \mathrm{~kb}$ of genomic sequence (Accession No. M84472). The results of the analysis for the first $17 \mathrm{~kb}$ of this sequence are shown. The bottom-most horizontal line is scaled in kilobases. Putative coding sequences are represented by GRAIL as flattened peaks along the next horizontal line. Thick bars above each peak delimit the exons as predicted by GRAIL. The location of the EDHB- 1 and -2 genes are shown by the thin horizontal lines. The presence of three novel exons is predicted by GRAIL. These putative exons are found to span the following positions: $2541-2769,4783-5391$, and 5459-5794 bp of the published sequence. cDNA clones were shown to contain these predicted exons spliced together and not the intervening genomic sequences.

Sequence of the cloned fragment revealed significant homology to a known transcript. The vacuolar proton pump 1 (VPP1), E1A- $f$, glucose-6-phosphatase, and $M O X 1$ genes are examples of cases in which the isolation of a single fragment provided sufficient information to infer that a clone was part of a bona fide gene. (2) The fragment is part of a cDNA clone. Intact cDNA library clones were isolated by the island rescue and direct screening methods. These clones are therefore considered "genes" for mapping purposes. DNA fragments cloned by exon amplification or direct selection were placed in the gene category only when they met criterion one or were successfully used as probes to isolate clones from cDNA libraries (criterion two).

In total, 26 genes were placed on the map. Fragments of 2 genes already known to map to this interval, $E D H 17 B 2$ and $P P Y$, were isolated. In addition, a previously unrecognized transcription unit was identified in genomic sequence of the $E D H B$ region (see above). We isolated fragments of two previously cloned genes: glucose-6-phosphatase (G6PT), the gene responsible for glycogen storage disease type 1a (Lei et al., 1993), and E1A-f, an ets-oncogene related transcription factor (Higashino et al., 1993). The precise chromosomal location of these genes was previously unknown, although the G6PT gene has been localized to chromosome 17 (Lei et al., 1994). Clones corresponding to three additional genes, the Ki antigen (Albertsen et al., 1994), MOX1 (Futreal et al., 1994a), and BRCA1 (Miki et al., 1994) were also independently isolated and mapped to this interval by others during the course of this work. Of the remaining 21 genes, 11 detect similar sequences in GenBank by BLAST analysis. Of these, 3 genes, HMG17 (Landsman et al., 1986, 1989), $\gamma$-tubulin (Zheng et $a l ., 1991$ ), and ribosomal protein L27 (Gallagher et al., 1994) are members of gene families. A fourth, the FLT4 tyrosine kinase (Aprelikova et al., 1992), hybridizes to specific cosmids from this interval and to additional sites in the genome. Sequence obtained to date from this cDNA clone is restricted to the $3^{\prime}$ untranslated region of the FLT4 gene (data not shown). In the absence of genomic sequence from this region, we are unable to determine whether the cDNAs isolated for these genes were transcribed from these exact loci on chromosome 17 or from the loci of other family members. Five additional genes appear to be human homologues of genes cloned from other species. As mentioned above, the human MOX1 clones isolated represent the human equivalent of this mouse gene (Futreal et al., 1994a).

The human vacuolar proton pump-1 cDNA shares 97\% amino acid identity over 29 residues with the 116$\mathrm{kDa}$ subunit of the bovine vacuolar proton pump (Peng et al., 1994). A rat gene probe was previously used to localize the human VPP-1 homologue to $17 \mathrm{q} 21$-qter in somatic cell hybrids (Ozcelik et al., 1991). The human Enhancer of Zeste $(E(z))$ gene shares $69 \%$ amino acid similarity with the Drosophila $E(z)$ gene, a negative regulator of the Antennapedia and Bithorax gene complexes (Jones and Gelbart, 1993). The complete cDNA sequence of the human $E(z)$ gene will be reported elsewhere (Abel et al., manuscript in preparation). Partial sequence of the human copper amine oxidase cDNA reveals a $77 \%$ amino acid identity over a 193-aminoacid segment with the bovine serum copper amine oxidase (Mu et al., 1994). The determination of the complete sequence of this gene is in progress. We have isolated a clone identical to a portion of EST-HFBCV14 (Adams $e t$ al., 1991), which we infer to be part of the human vesicle amine transporter-1 gene (VAT-1) by the virtue of the homology between the EST and Torpedo californica (Pacific electric ray) VAT-1 gene.

The GenBank/BLAST alignments of four genes revealed limited but significant similarity (smallest sum probability $<1 \times 10^{-5}$ ) to sequence in GenBank. Partial sequence of clone MTO-61 reveals limited homology (46\% amino acid identity in a 48-amino-acid overlap) to the rat and bovine neurexins (Ushkaryov and Sudhof, 1993). Exon clone MTO-134 shares $44 \%$ amino acid identity ( $82 \%$ similarity over a 29 -amino-acid overlap) to the human and chicken $23-\mathrm{kDa}$ component (p23) of the progesterone receptor complex (Johnson et al., 1994; Smith and Toft, 1992). The exon clone, MTO173 , is contained within cDNAs isolated with MTO-134 (data not shown). This exon does not share homology to the $p 23$ gene, suggesting that the homology between these two genes is limited. Sequence of the exon MTO192 reveals $70 \%$ amino acid similarity with the Caenorhabditis elegans and Saccharomyces cerevisiae premRNA splicing factors 22 and 16 (Company et al., 1991; Sultson et al., 1992). Additional cDNA-derived sequences demonstrate that this homology is restricted to the carboxyl half of these genes. (Ostermeyer et al., in preparation). The sequence of trapped exon clone MTO-122 is $40 \%$ identical and $60 \%$ similar (over a 60 amino-acid overlap) to the Xenopus int-2 (FGF-3) protein (Tannahill et al., 1992). This region is also common to mouse keratinocyte growth factor Fgf-7 (Dickson and Mason, 1993) and the DNA binding protein PRDII-BF1 (Fan and Maniatis, 1990).

Partial sequence from the seven remaining genes reveals no significant nucleotide or amino acid similari- 
ties to the entries in GenBank. It will be necessary to obtain full-length cDNA sequence of these genes before it can be determined whether they represent previously described transcription units.

ExST's. Our second map feature is products of exon amplification experiments that map to specific cosmids but have not detected cDNA clones in breast or fetal brain cDNA libraries after screening at least $5 \times 10^{5}$ recombinant phage. The complete sequence of these trapped exons has been determined and searched against GenBank; similar sequences were not located. These 39 unique clones in several cases appear to be clustered in the contig. Most notably, the 81C6 and 134A3 cosmids (Fig. 1) contain 10 ExST's. At least two other less impressive clusters are found in the contig (e.g., distal end of cosmid 90E4 and cosmid 32E5). Even though these exons are distributed across this area in a pattern resembling a gene, we have been unable to demonstrate either by sequence similarity to known genes or by the isolation of cDNAs that they belong to a contiguous transcription unit. A likely explanation for this is that an insufficient number of tissues or developmental stages have been surveyed for expression. It is also possible that a more sensitive test such as RT-PCR will be required to detect low-level transcripts from these areas. Further studies will be needed to determine whether these ExST's are constituents of true transcription units or artifacts of the exon amplification process.

ESTs. The third category is ESTs. These clones are the products of direct selection experiments. Because they are products amplified from a cDNA library, they represent fragments of transcribed sequences. Sufficient evidence does not exist to classify them as genes as outlined above. As is the case for the ExST's, the sequences of these fragments are not similar to sequences in the public databases. Like many randomly generated ESTs (Adams et al., 1991), these fragments are of unknown function. Unlike the majority of ESTs, the precise chromosomal location of these putative genes is now known.

In conclusion, we have isolated transcripts from approximately $600 \mathrm{~kb}$ of the human genome. It is likely that this interval of the genome contains at least 26 unique genes. Although we are unable to calculate the exact gene density of this region, our finding of 1 gene approximately every $20 \mathrm{~kb}$ is close to the value expected if the human genome contains 100,000 randomly distributed genes (e.g., 1 gene per $30 \mathrm{~kb}$ ). This transcript map and further refinements thereof will add to our knowledge of genome structure, gene organization, and expression.

\section{ACKNOWLEDGMENTS}

The authors thank Joan Effiom for assistance in the preparation of the manuscript and Sonye Danoff for critical reading and helpful suggestions. This work was supported by NIH Grant CA57601 (B.W.).
Note added in proof. The cloning of the human homologue of yeast Prp22 has recently been reported by Y. Ono, M. Ohno, and Y. Shimura (1994). Mol. Cell. Biol. 14: 7611-7620. The sequence of the cDNA clone designated by Ono as HRH1 is identical to the Prp22 clones reported in this paper.

\section{REFERENCES}

Abel, K. J., Castilla, L. H., Buckler, A. J., Couch, F. J., Ho, P., Schaefer, I., Chandrasekharappa, S. C., Collins, F. S., and Weber, B. (1994). Isolation of gene sequences from the BRCA1 region of chromosome $17 \mathrm{q} 21$ by exon amplification. In "Identification of Transcribed Sequences" (U. Hochgeschwender and K. Gardiner, Eds.), pp. 183-198, Plenum, New York.

Adams, M. D., Kelley, J. M., Gocayne, J. D., Dubnick, M., Polymeropoulos, M. H., Xiao, H., Merril, C. R., Wu, A., Olde, B., Moreno, R. F., Kerlavage, A. R., McCombie, W. R., and Venter, J. C. (1991). Complementary DNA sequencing: Expressed sequence tags and the human genome project. Science 252: 1651-1656.

Albertsen, H. M., Smith, S. A., Mazoyer, S., Fujimoto, E., Stevens, J., Williams, B., Rodriguez, P., Cropp, C. S., Slijepcevic, P., Carlson, M., Robertson, M., Bradley, P., Lawrence, E., Harrington, T., Mei Sheng, Z., Hoopes, R., Sternberg, N., Brothman, A., Callahan, R., Ponder, B. A. J., and White, R. (1994). A physical map and candidate genes in the BRCA1 region on chromosome 17q12-21. Nature Genet. 7: 472-479.

Altschul, S. F., Gish, W., Miller, W., Myers, E. W., and Lipman, D. J. (1990). Basic local alignment search tool. J. Mol. Biol. 215: 403-410.

Aprelikova, O., Pajusola, K., Partanen, J., Armstrong, E., Alitalo, R., Bailey, S. K., McMahon, J., Wasmuth, J., Huebner, K., and Alitalo, K. (1992). FLT4, a novel class III receptor tyrosine kinase in chromosome 5q33-qter. Cancer Res. 52: 746-748.

Bowcock, A. M., Anderson, L. A., Friedman, L. S., Black, D. M., Osborne-Lawrence, S., Rowell, S. E., Hall, J. M., Solomon, E., and King, M.-C. (1993). THRA and D17S183 flank an interval of $4 \mathrm{cM}$ for the breast-ovarian-cancer gene (BRCA1). Am. J. Hum. Genet. 52: 718-722.

Buckler, A. J., Chang, D. D., Graw, S. L., Brook, J. D., Haber, D. A., Sharp, P. A., and Housman, D. E. (1991). Exon amplification: A strategy to isolate mammalian genes based on RNA splicing. Proc. Natl. Acad. Sci. USA 88: 4005-4009.

Campbell, I. G., Nicolai, H. M., Foulkes, W. D., Senger, G., Stamp, G. W., Allan, G., Boyer, C., Jones, K., Bast, R. C., Soloman, E., Trowsdale, J., and Black, D. M. (1994). A novel gene encoding a B-box protein within the BRCA1 region at 17q21.1. Hum. Mol. Genet. 3: 589-594.

Chamberlain, J. S., Boehnke, M., Frank, T. S., Kiousis, S., Xu, J., Guo, S.-W., Hauser, E. R., Norum, R. A., Helmbold, E. A., Markel, D. S., Keshavarzi, S. M., Jackson, C. E., Calzone, K., Garber, J., Collins, F. S., and Weber, B. L. (1993). BRCA1 maps proximal to D17S579 on chromosome $17 \mathrm{q} 21$ by genetic analysis. Am. J. Hum. Genet. 52: 792-798.

Church, D. M., Stotler, C. J., Rutter, J. L., Murrell, J. R., Trofatter, J. A., and Buckler, A. J. (1994). Isolation of genes from complex sources of mammalian genomic DNA using exon amplification. $\mathrm{Na}$ ture Genet. 6: 98.

Collins, F. S. (1992). Positional cloning: Let's not call it reverse any more. Nature Genet. 1: 3-6.

Collins, F. S., and Galas, D. (1993). A new five year plan for the U.S. Human Genome Project. Science 262: 43.

Company, M., Arenas, J., and Abelson, J. (1991). Requirement of the RNA helicase-like protein PRP22 for release of messenger RNA from spliceosomes. Nature 349: 487-493.

Couch, F. J., Castilla, L. H., Xu, J., Abel, K. A., Welcsh, P., King, S. E., Wong, L., Ho, P. P., Merajver, S., Brody, L. C., Yin, G., Hayes, S. T., Geiser, L. M., Flejter, W. L., Glover, T. W., Friedman, L. S., Lynch, E. D., Meza, J. E., King, M.-C., Law, D. J., Deaven, L., Bowcock, A. M., Collins, F. S., Weber, B. L., and 
Chandrasekharappa, S. C. (1995). A YAC-, P1-, and cosmid-based physical map of the BRCA1 region on chromosome $17 \mathrm{q} 21$. Genomics 25: 264-273.

Couch, F. J., Weber, B. L., Collins, F. S., Tagle, D. A. (1994). Isolation of expressed sequences from the chromosome 17q21 BRCA1 region by magnetic bead capture. In "Identification of Transcribed Sequences" (U. Hochgeschwender and K. Gardiner, Eds.), pp. 5163, Plenum, New York.

Dickson, C., and Mason, I. J. (1993). FGF-7 keratinocyte growth factor expression during mouse development suggests roles in myogenesis, forebrain regionalisation and epithelial-mesenchymal interaction. EMBL Accession No. Z22703.

Duyk, G. M., Kim, S., Myers, R. M., and Cox, D. R. (1990). Exon trapping: A genetic screen to identify candidate transcribed sequences in cloned mammalian genomic DNA. Proc. Natl. Acad. Sci. USA 87: 8995-8999.

Easton, D. F., Bishop, D. T., Ford, D., and Crockford, G. P. (1993). The breast cancer linkage consortium: Genetic linkage analysis in familial breast and ovarian cancer-Results from 214 families. Am. J. Hum. Genet. 52(4): 678-701.

Fan, C. M., and Maniatis, T. (1990). A DNA-binding protein containing two widely separated zinc finger motifs that recognize the same DNA sequence. Genes Dev. 4: 29-42.

Feinberg, A. P., and Vogelstein, B. (1983). A technique for radiolabeling DNA restriction fragments to high specific activity. Anal. Biochem. 132: 6

Friedman, L. S., Lynch, E. D., and King, M. C. (1993). Two independent polymorphisms at the $17 \beta$-hydroxysteroid dehydrogenase (EDH17B) gene (17q21). Hum. Mol. Genet. 2: 821.

Friedman, L. S., Ostermeyer, E. A., Lynch, E. D., Welcsh, P., Szabo, C. I., Meza, J. E., Anderson, L. A., Dowd, P., Lee, M. K., Rowell, S. E., Ellison, J., Boyd, J., and King, M.-C. (1995), 22 genes from chromosome 17q21: Cloning, sequencing, and characterization of mutations in breast cancer families and tumors. Genomics 25: 256-263.

Futreal, P. A., Cochran, C., Rosenthal, J., Miki, Y., Swenson, J., Hobbs, M., Bennett, L. M., Haugen-Strano, A., Marks, J., Barrett, J. C., Tavtigian, S. V., Shattuck-Eidens, D., Kamb, A., Skolnick, M., and Wiseman, R. W. (1994a). Isolation of a diverged homeobox gene, MOX1, from the BRCA1 region on $17 \mathrm{q} 21$ by solution hybrid capture. Hum. Mol. Genet. 3: 1359-1364.

Futreal, A. P., Liu, Q., Shattuck-Eidens, D., Cochran, C., Harshman, K., Tavtigian, S., Bennett, L. M., Haugen-Strano, A., Swensen, J., Miki, Y., Eddington, K., McClure, M., Frye, C., Weaver-Feldhaus, J., Ding, W., Gholami, Z., Soderkvist, P., Terry, L., Jhanwar, S., Berchuck, A., Iglehart, J. D., Marks, J., Ballinger, D. G., Barrett, J. C., Skolnick, M. H., Kamb, A., and Wiseman, R. (1994b). BRCA1 mutations in primary breast and ovarian carcinomas. Science 266: $120-122$.

Gallagher, R. A., McClean, P. M., and Malik, A. N. (1994). Cloning and nucleotide sequence of a full length $\mathrm{cDNA}$ encoding ribosomal protein L27 from human fetal kidney. Biochim. Biophys. Acta 1217: $329-332$.

Gish, W., and States, D. J. (1993). Identification of protein coding regions by database similarity search. Nature Genet. 3: 266-272.

Hall, J. M., Lee, M. K., Newman, B., Morrow, J. E., Anderson, L. A., Huey, B., and King, M.-C. (1990). Linkage of early onset breast cancer to chromosome 17q21. Science 250: 1684-1689.

Higashino, F., Yoshida, K., Fujinaga, Y., Kamio, K., and Fujinaga, K. (1993). Isolation of a cDNA encoding the adenovirus E1A enhancer binding protein: A new human member of the ets oncogene family. Nucleic Acids Res. 21: 547.

Johnson, J. L., Beilo, T. G., Krco, C. J., and Toft, D. O. (1994). Characterization of a novel 23-kilodalton protein of unactive progesterone receptor complexes. Mol. Cell. Biol. 14: 1956-1963.

Jones, R. S., and Gelbart, W. M. (1993). The drosophila polycombgroup gene enhancer of zeste contains a region with sequence similarity to trithorax. Mol. Cell. Biol. 13: 6357-6366.

Kamb, A., Futreal, P. A., Rosenthal, J., Cochran, C., Harshman,
K. D., Liu, Q., Phelps, R. S., Tavtigian, S. V., Tran, T., Hussey, C., Bell, R., Miki, Y., Swensen, J., Hobbs, M. R., Marks, J., Bennett, L. M., Barrett, J. C., Wiseman, R. W., and Shattuck-Eidens, D. (1994). Lacalization of the VHR phosphatase gene and its analysis as a candidate for BRCA1. Genomics 23: 163-167.

Krizman, D. B., and Berget, S. M. (1993). 3'-Terminal exon trapping: Identification of genes from vertebrate DNA. Focus 15: 106-108.

Landsman, D., Soares, N., Gonzalez, F. J., and Bustin, M. (1986). Chromosomal protein HMG-17: Complete human cDNA sequence and evidence for a multigene family. J. Biol. Chem. 261: 74797484.

Landsman, D., McBride, O. W., and Bustin, M. (1989). Human nonhistone chromosomal protein HMG-17: Identification, characterization, chromosome localization and RFLPs of a functional gene from the large multigene family. Nucleic Acids Res. 17: 23012314.

Leach, R. J., Thayer, M. J., Schafer, A. J., and Fournier, R. E. K. (1989). Physical mapping of human chromosome 17 using fragment-containing microcell hybrids. Genomics 5: 167-176.

Lei, K. J., Pan, C. J., Shelly, L. L., Liu, J. L., and Chou, J. Y. (1994). Identification of mutations in the gene for glucose-6-phosphatase, the enzyme deficient in glycogen storage disease type 1A. J. Clin. Invest. 93: 1994-1999.

Lei, K. J., Shelly, L. L., Pan, C. J., Sidbury, J. B., and Chou, J. Y. (1993). Mutations in the glucose-6-phosphatase gene that cause glycogen storage disease type 1a. Science 262: 580-583.

Lovett, M., Kere, J., and Hinton, L. M. (1991). Direct selection: A method for the isolation of cDNAs encoded by large genomic regions. Proc. Natl. Acad. Sci. USA 88: 9628-9632.

Miki, Y., Swensen, J., Shattuck-Eidens, D., Futreal, P. A., Harshman, K., Tavtigian, S., Liu, Q., Cochran, C., Bennett, L. M., Ding, W., Bell, R., Rosenthal, J., Hussey, C., Tran, T., McClure, M., Frye, C., Hattier, T., Phelps, R., Haugen-Strano, A., Katcher, H., Yakumo, K., Gholami, Z., Shaffer, D., Stone, S., Bayer, S., Wray, C., Bogden, R., Dayananth, P., Ward, J., Tonin, P., Narod, S., Bristow, P. K., Norris, F. H., Helvering, L., Morrison, P., Rosteck, P., Lai, M., Barrett, J. C., Lewis, C., Neuhausen, S., Cannon-Albright, L., Goldgar, D., Wiseman, R., Kamb, A., and Skolnick, M. H. (1994). A strong candidate for the breast and ovarian cancer susceptibility gene BRCA1. Science 266: 66 .

Mu, D., Medzihradszky, K. F., Adams, G. W., Mayer, P., Hines, W. M., Burlingame, A. L., Smith, A. J., Cai, D., and Klinman, J. P. (1994). Primary structures for a mammalian cellular and serum copper amine oxidase. J. Biol. Chem. 269: 9926-9932.

Narod, S. A., Feuteun, J., Lynch, H. T., Watson, P., Conway, T., Lynch, J., and Lenoir, G. M. (1991). Familial breast-ovarian cancer locus on chromosome 17q12-23. Lancet 338: 82-83.

Oliver, S. G., van der Aart, Q. J., Agostoni-Carbone, M. L., Aigle, M., Alberghina, L., Alexandraki, D., Antoine, G., Anwar, R., and Ballesta, J. P. (1992). The complete DNA sequence of yeast chromosome III. Nature 357: 38-46.

Osborne-Lawrence, S., Welcsh, P. L., Spillman, M., Chandrasekharappa, S. C., Gallardo, T. D., Lovett, M., and Bowcock, A. M. (1995). Direct selection of expressed sequences within a $1-\mathrm{Mb}$ region flanking BRCA1 on human chromosome 17q21. Genomics 25: 248255.

Ozcelik, T., Sudhof, T. C., and Francke, U. (1991). Chromosomal assignments of genes for vacuolar (endomembrane) proton pump subunits VPP1/Vpp-1 (116 kDa) and VPP3/Vpp-3 (58 kDa) in human and mouse (Abstract). Cytogenet. Cell Genet. 58: 2008-2009.

Parimoo, S., Patanjali, S. R., Shukla, H., Chaplin, D. D., and Weissman, S. M. (1991). cDNA selection: Efficient PCR approach for the selection of cDNAs encoded in large chromosomal DNA fragments. Proc. Natl. Acad. Sci. USA 88: 9623-9627.

Patel, K., Cox, R., Shipley, J., Kiely, F., Frazer, K., Cox, D. R., Lehrach, H., and Sheer, D. (1991). A novel and rapid method for isolating sequences adjacent to rare cutting sites and their use in physical mapping. Nucleic Acids Res. 19: 4371-4375.

Peltoketo, H., Isomaa, V., Maeentausta, O., and Vihko, R. (1988). 
Complete amino acid sequence of human placental 17-beta-hydroxysteroid dehydrogenase deduced from cDNA. FEBS Lett. 239: 73-77.

Peng, S. B., Crider, B. P., Xie, X. S., and Stone, D. K. (1994). Alternative mRNA splicing generates tissue-specific isoforms of $116-\mathrm{kDa}$ polypeptide of vacuolar proton pump. J. Biol. Chem. 269: 1726217266.

Sambrook, J., Fritsch, E. F., and Maniatis, T. (1989). "Molecular Cloning: A Laboratory Manual," 2nd ed., Cold Spring Harbor Laboratory Press, Cold Spring Harbor, NY.

Shah, M. B., Guan, X., Einstein, J. R., Matis, S., Xu, Y., Mural, R. J., and Uberbacher, E. C. (1994). User's guide to GRAIL and GENQUEST (sequence analysis, gene assembly and sequence comparison systems) e-mail servers and XGRAIL (Version 1.2) and XGENQUEST (Version 1.1) client-server systems. Available by anonymous $\mathrm{ftp}$ to arthur.epm.ornl.gov (128.219.9.76) from directory pub/xgrail or pub/xgenQuest as file Manual.grail-genquest.

Simard, J., Feuteun, J., Lenoir, G., Tonin, P., Normand, T., LuuThe, V., Vivier, A., Lasko, D., Morgan, K., Rouleau, G. A., Lynch, H., Labrie, F., and Narod, S. A. (1993). Genetic mapping of the breast-ovarian cancer syndrome to a small interval on chromosome 17q12-21: Exclusion of candidate genes EDH17B2 and RARA. Hum. Mol. Genet. 2: 1193-1199.

Smith, D. F., and Toft, D. O. (1992). Composition, assembly and activation of the avian progesterone receptor. J. Steroid Biochem. Mol. Biol. 41: 201-207.

Smith, S. A., DiCioccio, R. A., Struewing, J. P., Easton, D. F., Gallion, H. H., Albertsen, H., Mazoyer, S., Johansson, B., Steichen-Gersdorf, E., Stratton, M., Ford, D., Marshall, G., White, R. L., Piver, M. S., and Ponder, B. A. J. (1994). Localisation of the breastovarian cancer susceptibility gene (BRCA1) on $17 \mathrm{q} 12-21$ to an interval of $\leqslant 1 \mathrm{cM}$. Genes Chrom. Cancer 10: 71-76.

Sultson, J., Du, Z., Thomas, K., Wilson, R., Hillier, L., Staden, R., Halloran, N., Green, P., Thierry-Mieg, J., Qiu, L., Dear, S., Coulson, A., Craxton, M., Durbin, R., Berks, M., Metzstein, M.,
Hawkins, T., Ainscough, R., and Waterson, R. (1992). The C. elegans genome sequencing project: A beginning. Nature 356: 37-41. Swaroop, A., and Xu, J. (1993). cDNA libraries from human tissues and cells lines. Cytogenet. Cell Genet. 64: 292.

Tagle, D. A., Swaroop, M., Lovett, M., and Collins, F. S. (1993). Magnetic bead capture of expressed sequences within large genomic segments. Nature 161: 751-756.

Tannahill, D., Isaacs, H. V., Close, M. J., Peters, G., and Slack, J. M. (1992). Developmental expression of the xenopus int-2 (FGF3) gene: Activation by mesodermal and neural induction. Development 115: 695-702.

Uberbacher, E. C., and Mural, R. J. (1991). Locating protein-coding regions in human DNA sequences by a multiple sensor-neural network approach. Proc. Natl. Acad. Sci. USA 88: 11261-11265.

Ushkaryov, Y. A., and Sudhof, T. C. (1993). Neurexin III alpha: Extensive alternative splicing generates membrane-bound and soluble forms. Proc. Natl. Acad. Sci. USA 90: 6410-6414.

Valdes, J. M., Tagle, D. A., and Collins, F. S. (1994). Island rescue PCR: A rapid and efficient method for isolating transcribed sequences from yeast artificial chromosomes and cosmids. Proc. Natl. Acad. Sci. USA 91: 5377-5381.

Wallace, M. R., Marchuk, D. A., Anderson, L. B., Letcher, R., Odeh, H. M., Saulino, A. M., Fountain, J. W., Brereton, A., Nicholson, J., and Mitchell, A. L. (1990). Type I neurofibromatosis gene: Identification of a large transcript disrupted in three NFL patients. Science 249: 181-186.

Weber, B. L., Abel, K., Brody, L. C., Flejter, W. L., Chandrasekharappa, S. C., Couch, F. J., Merajver, S. D., and Collins, F. S. (1994). Familial breast cancer: Approaching the isolation of a susceptibility gene. Cancer 74: 1013-1020.

Westin, G., Zabielski, J., Hammarstrom, K., Monstein, H., Bark, C., and Pettersson, U. (1984). Clustered genes for human U2 RNA. Proc. Natl. Acad. Sci. USA 81: 3811-3815.

Zheng, Y., Jung, M. K., and Oakley, B. R. (1991). Gamma-tubulin is present in Drosophila melanogaster and Homo sapiens and associated with the centrosome. Cell 65: 817-823. 